\title{
Risk factors for corneal endothelial cell loss by cataract surgery in eyes with pseudoexfoliation syndrome
}

This article was published in the following Dove Press journal:

Clinical Ophthalmology

30 August 2016

Number of times this article has been viewed

\author{
Yumi Hasegawa ${ }^{1,2}$ \\ Ryohei Nejima' \\ Yosai Mori' \\ Toshihiro Sakisaka' \\ Keiichiro Minami' \\ Kazunori Miyata' \\ Tetsuro Oshika ${ }^{2}$ \\ 'Miyata Eye Hospital, Miyazaki, \\ ${ }^{2}$ Department of Ophthalmology, \\ Faculty of Medicine, University \\ of Tsukuba, Ibaraki, Japan
}

Correspondence: Yumi Hasegawa Department of Ophthalmology, Faculty of Medicine, University of Tsukuba, I-I-I Tennoudai, Tsukuba, Ibaraki 305-8575, Japan

$\mathrm{Tel} / \mathrm{fax}+8 \mid 298533148$

Email tam_ylı0@yahoo.co.jp
Purpose: The aim of this study was to investigate the factors associated with decreases in corneal endothelial cell density (ECD) resulting from cataract surgery in eyes with pseudoexfoliation syndrome (PEX).

Methods: The clinical records of 78 eyes of 78 patients with PEX who had undergone cataract surgery were reviewed. ECD was measured preoperatively and at 3 months postoperatively with specular microscopy. Multiple regression analysis was used to assess the factors that were significantly related to the rate of ECD loss. Explanatory variables included age, preoperative ECD, pupil diameter, cataract grade, concomitance of glaucoma or diabetes mellitus, preoperative anterior chamber depth, surgery time, total time and power of ultrasound, performance of intraoperative pupillary enlargement manipulation, and postoperative aqueous flare intensity at 1 week and 1 month.

Results: ECD before and after surgery was 2,464 \pm 337 cells $/ \mathrm{mm}^{2}$ and 2,400 \pm 347 cells $/ \mathrm{mm}^{2}$, respectively, with an ECD loss rate of $2.6 \% \pm 5.1 \%$ (mean $\pm \mathrm{SD}$ ). Multiple regression analysis revealed that ECD loss was significantly associated with the cataract grade $(P=0.019)$ and preoperative anterior chamber depth $(P=0.023)$.

Conclusion: With modern small incision cataract surgery, the ECD loss varied with surgical invasions due to severe cataract and shallow anterior chamber, and the presence of PEX was least affected.

Keywords: pseudoexfoliation syndrome, corneal endothelial cell loss, cataract surgery

\section{Introduction}

Pseudoexfoliation syndrome (PEX) is a common clinical condition that is characterized by the development of white and dandruff-like flakes in the anterior segments and is often associated with decreases and morphological changes in corneal endothelial cells. ${ }^{1,2}$ It is known that the presence of PEX aggravates the risk of intraoperative complications during cataract surgery because of poor pupil dilation and fragile zonules. ${ }^{3-6}$ However, whether PEX is a risk factor for reduction in corneal endothelial cell density (ECD) after cataract surgery is still controversial. One study showed that a reduction in ECD was significantly greater in eyes with PEX, ${ }^{7}$ whereas other studies reported contradictory findings. ${ }^{8-10}$ There are inherent difficulties in comparative assessments of ECD between eyes with and without PEX. First, advanced patient age ${ }^{11,12}$ and the presence of $\mathrm{PEX}^{1,2}$ negatively affect ECD regardless of the performance of cataract surgery; thus, preoperative matching between the two groups is not easy. Second is the accuracy of the ECD assessment; variance in ECD counting is reported to be $6 \%$, 
even when images of excellent quality are used. ${ }^{13}$ Furthermore, ECD counting may vary by $2 \%-5 \%$ when several examiners are involved. ${ }^{11}$

Because designing a well-controlled comparative study is difficult, a factor analytical study of multiple parameters that may influence ECD should be considered. To our knowledge, such a factor analysis has rarely been reported. Kaljurand and Teesalu revealed that ultrasound (US) power and patient age were significant factors for ECD reduction. ${ }^{9}$ Polymethyl methacrylate intraocular lenses were implanted through enlarged incisions, so that the reductions in ECD were high in both groups (18.1\% and $11.6 \%$ in the PEX and control groups, respectively). Hence, the results cannot be applied to the current small incision cataract surgery. The purpose of this study was to investigate the factors associated with reduction in ECD when eyes with PEX underwent modern small incision cataract surgery.

\section{Methods}

This retrospective study was performed in accordance with the Declaration of Helsinki, and the study protocol was approved by the ethics review board of Miyata Eye Hospital. Written informed consent for use of the clinical data was obtained from all patients. The clinical records of patients who had eyes with PEX and who had undergone cataract surgery from June 2010 to May 2013 were reviewed. The inclusion criteria were an eye with PEX that was diagnosed preoperatively under slit lamp microscopy and an eye that had undergone cataract surgery with phacoemulsification and aspiration and intraocular lens implantation into the capsular bag. In cases of bilateral cataract surgery, the first eye was included for analysis. Eyes with corneal pathologies, uveitis, history of other intraocular surgery, laser iridotomy, combined surgery with trabeculectomy or vitrectomy, conversion to extracapsular cataract extraction, intraocular surgery during postoperative observation duration, and patients who were younger than 60 years were excluded.

Before cataract surgery, ECD, anterior chamber depth (ACD), and dilated pupil diameter were examined. ECD in the center of the cornea was measured using a specular microscope (FA-3509; KONAN MEDICAL, Nishinomiya, Hyogo, Japan), and experienced examiners selected the reference cells for counting the ECD with the installed software. ACD was measured using the ultrasonic A-scan pachymetry. The severity of the cataract was graded using the Emery-Little classification. The concomitance of diabetes mellitus and glaucoma was also recorded.

All cataract surgeries were performed by experienced surgeons using an INFINITI Vision System (Alcon
Laboratories, Inc., Fort Worth, TX, USA). After creating a superior scleral incision of 2.2-2.4 $\mathrm{mm}$ in width, the cataract was removed with phacoemulsification and aspiration, while the corneal endothelial cells were protected using the softshell technique. ${ }^{14}$ When pupillary dilation was insufficient, the pupil was enlarged by multiple partial sphincterotomies or the use of iris expanders. In cases of zonular dialysis, a capsular tension ring was used. Surgery time and the time (US time) and total power (US total power) of the ultrasonic that was applied were recorded.

The ECD was measured 3 months after surgery, and the reduction rate in ECD was calculated. The aqueous flare intensity was measured using a laser flare meter (FM-500; Kowa, Nagoya, Aichi, Japan) at 1 week and 1 month postoperatively.

Factors related to the reduction rate in ECD were evaluated by using multiple regression analysis. First, the cross-correlation and principal factor analyses were conducted for excluding the parameters that would have led to multicollinearity with other parameters. Then, step-wise multiple regression analysis with respect to the reduction rate in ECD was performed with the selected parameters. The results are expressed as the mean $\pm \mathrm{SD}$ for continuous variables and as frequencies and percentages for categorical variables. A $P$-value of $<0.05$ was considered as statistically significant.

\section{Results}

Seventy-eight eyes of 78 patients ( 23 men and 55 women) were enrolled. The mean age of the patients was $78.2 \pm 6.8$ years (range 63-93 years). Surgery was performed by seven experienced surgeons. Table 1 shows the preoperative, intraoperative, and postoperative demographic data. Preoperatively, the ECD was $2,464 \pm 337$ cells $/ \mathrm{mm}^{2}$, and 3 months postoperatively, the ECD was $2,400 \pm 347$ cells $/ \mathrm{mm}^{2}$, giving a reduction rate of ECD of $2.6 \% \pm 5.1 \%$ ranging from $-6.4 \%$ to $18.4 \%$. With the sample size and a significance level of $5 \%$, the detection power in multiple regression analysis of the two factors was anticipated to be $75 \%$ when $R^{2}$ was 0.10 .

The parameters used in the multiple regression analysis resulted in patient age, preoperative ECD, dilated pupil diameter, cataract grade, concomitance of diabetes mellitus or glaucoma, preoperative ACD, surgery time, US time, US total power, pupillary enlargement, and aqueous flare intensity at 1 week and 1 month postoperatively. The analysis yielded a significant multiple correlation $\left(R^{2}=0.12, P=0.006\right)$, and the final linear regression model included significant parameters of the cataract grade $(P=0.019)$ and preoperative ACD $(P=0.023)$ (Table 2$)$. The ECD was reduced by $1.39 \%$ with 
Table I Perioperative parameters in eyes with pseudoexfoliation syndrome

\begin{tabular}{ll}
\hline Parameter & Mean \pm SD (range) \\
\hline Preoperative & \\
ACD $(\mathrm{mm})$ & $3.06 \pm 0.37(2.17-4.08)$ \\
ECD (cells/mm²) & $2,464 \pm 337(1,374-3,165)$ \\
Dilated pupil diameter $(\mathrm{mm})$ & $5.72 \pm 0.95(3.0-8.0)$ \\
Cataract grade (Emery-Little) & $1.64 \pm 0.97$ (grade I: 48 eyes; grade 2: \\
& 16 eyes; grade 3: nine eyes; grade 4: \\
& four eyes; and grade 5: one eye) \\
Diabetes mellitus/glaucoma & $13 / 17$ \\
(eyes) & \\
Intraoperative & \\
Surgery time (minutes) & $14.6 \pm 5.7(6.0-30.3)$ \\
US time (seconds) & $88.6 \pm 30.9(37-177)$ \\
US total power (\%minutes) & $26.7 \pm 12.7(5.9-76.1)$ \\
Pupillary enlargement & 24 (expander: I7 and \\
manipulation (eyes) & sphincterotomies: 7) \\
Postoperative & \\
ECD (cells/mm²) & $2,400 \pm 347(1,332-3,226)$ \\
Aqueous flare intensity & \\
I week & $13.4 \pm 7.3(4.2-38.1)$ \\
I month & $13.5 \pm 7.2(3.9-41.3)$ \\
\hline
\end{tabular}

Abbreviations: $A C D$, anterior chamber depth; $E C D$, endothelial cell density; US, ultrasound; SD, standard deviation.

a step of the Emery-Little classification and by $3.45 \%$ with a $1 \mathrm{~mm}$ decrease in the preoperative ACD. Figures 1 and 2 show the relationships between the reduction rate in ECD and cataract grade (the Emery-Little classification) as well as the preoperative ACD.

\section{Discussion}

In the current study, the reduction rate in ECD was $2.6 \% \pm 5.1 \%$. In previous studies, the reduction rate in ECD due to cataract surgery in PEX eyes was reported to be $9.0 \%$ at 3 months postoperation, ${ }^{7} 11.1 \%$ at 6 months postoperation, ${ }^{8}$ and $18.1 \%$ at 1 month postoperation. ${ }^{9}$ The difference from the current study might be because of differences in the preoperative $\mathrm{ECD}$, patient ages, and surgical procedure. The current study used a small incision, the soft-shell technique,

Table 2 Results of multivariable regression analysis to show the parameters significantly associated with ECD loss

\begin{tabular}{llll}
\hline Parameter & $\begin{array}{l}\text { Regression } \\
\text { coefficient }\end{array}$ & $\mathbf{9 5 \%} \mathbf{~ C l}$ & P-value \\
\hline Cataract grade & 1.39 & $0.24-2.55$ & 0.019 \\
Preoperative ACD & -3.45 & -6.40 to -0.49 & 0.023 \\
Concomitance of & -3.00 & -5.97 to 0.01 & 0.051 \\
diabetes mellitus & & & \\
Constant & & $1.87-20.77$ & 0.020 \\
\hline
\end{tabular}

Abbreviations: $A C D$, anterior chamber depth; $E C D$, endothelial cell density; $\mathrm{Cl}$, confidence interval.

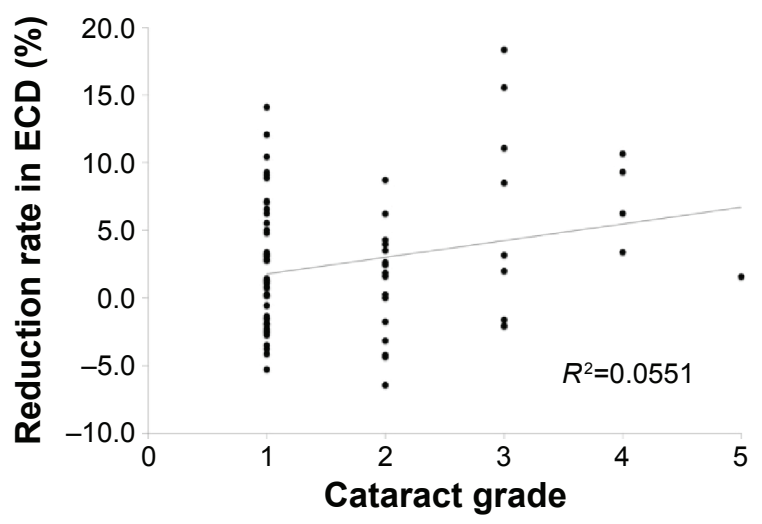

Figure I Relationship between the ECD reduction rate and cataract grade. Notes: The reduction rate was significantly associated with the cataract grade (the Emery-Little classification). Solid line denotes a regression equation obtained by multiple regression analysis $\left(R^{2}=0.12, P=0.006\right)$.

Abbreviation: ECD, endothelial cell density.

and surgical instruments equipped with sophisticated intraoperative fluidics.

The current study showed a significant association of the cataract grade. In eyes without PEX, a higher density cataract needs more US time and US total power, ${ }^{15,16}$ resulting in a significant increase in the risk of ECD reduction. ${ }^{10,15,17,18}$ The previous comparison between PE and control eyes showed no significant differences in the cataract grade and the reduction in ECD. ${ }^{19}$ Thus, the reduction in ECD resulting from the cataract grade was not considered to be PEX related.

The other parameter that significantly affected the reduction in ECD was preoperative ACD. A shallower anterior chamber reduced ECD more after cataract surgery. An in vitro investigation shows that corneal endothelial cell damage decreased with the distance to the phacoemulsification tip. ${ }^{20}$ In eyes without PEX, a population-based study revealed that eyes with shallower ACDs had an anatomically shorter ocular axial length ${ }^{21}$ and that a short ocular axial length was a risk for

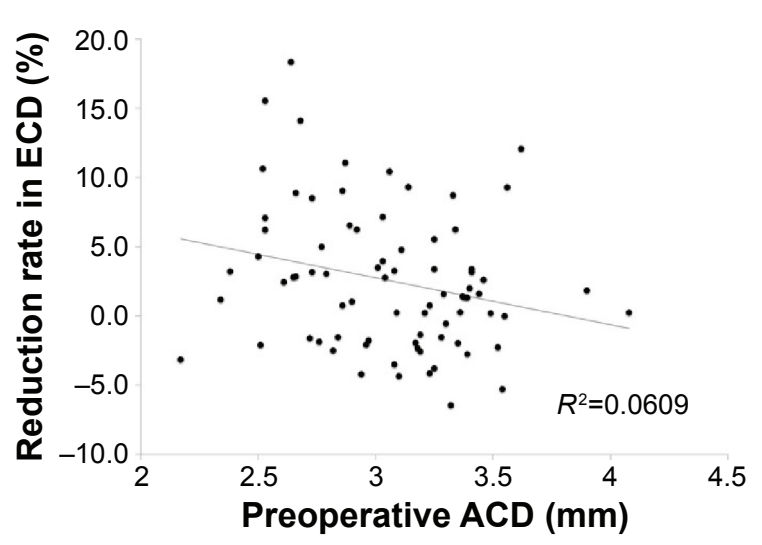

Figure 2 Relationship between the rate of ECD loss and preoperative ACD. Note: The rate of ECD loss was significantly associated with preoperative ACD (the multiple step-wise regression analysis).

Abbreviations: $A C D$, anterior chamber depth; $E C D$, endothelial cell density. 
ECD reduction after cataract surgery. ${ }^{18,22}$ Comparison of the ACD between eyes with and without PEX is still unknown; Arnarsson et $\mathrm{al}^{23}$ reported no difference, while Zheng et $\mathrm{al}^{24}$ found significantly shallower ACD in eyes with PEX. To date, concluding that preoperative ACD was related with PEX is difficult. Further investigations will be necessary.

The intraoperative pupillary size is significantly smaller in eyes with PEX. ${ }^{4,7,25}$ Insufficient mydriasis is a risk of intraoperative complications, such as posterior capsule rupture and vitreous loss. ${ }^{26}$ The current study applied pupillary enlargement for cases of poor pupillary dilatation. Although the pupillary enlargement increased surgery time, there was no significant reduction in ECD, suggesting that pupillary enlargement to secure a sufficient working space during phacoemulsification was effective and safe in eyes with PEX.

There are limitations in the current study. First, the severity of PEX was not assessed. Zimmermann et $\mathrm{al}^{27}$ classified eyes into two grades based on the amount of visible PEX deposits on the crystalline lens, and eyes with a more severe PEX grade compromised ECD, and showed that ECD decreased with higher PEX grades. In the current study, such grading was not available. Second, the retrospective study examined the ECD only, and a morphological analysis of corneal endothelial cells was not performed. After cataract surgery in eyes with PEX, the sizes of the corneal endothelial cells were increased and the cell shape became more variable. ${ }^{7}$ Morphological analyses, such as of the rate of the hexagonal cells and variation in cell size, might be more sensitive indicators. Third, there was no control group in the current study. Comparative assessments of ECD inherently pose difficulties in matching preoperative demographics and accuracy of the ECD assessment, whereas the comparison of reduction in ECD and patient's demographics demonstrates no significant difference, ${ }^{19}$ which supported the analysis results in the current study. Hence, we concluded that the current analysis with no control group would be effective.

\section{Conclusion}

The current study indicated that a higher cataract grade and shallower preoperative anterior chamber are risk factors for ECD reduction after cataract surgery in eyes with PEX. These two factors are not unique to PEX, and there has been no known difference in such parameters between eyes with and without PEX. Thus, it is suggested that corneal endothelial cell damage in eyes with PEX is attributable to surgical invasion itself and it is not clear at present whether the presence of PEX further added to an ECD reduction.

\section{Acknowledgments}

This report was presented at the ARVO Annual Meeting-May 04-08, 2014, in Orlando, FL, USA, as a poster presentation with interim findings. The poster's abstract was published in "Poster Abstracts" in Investigative Ophthalmology \& Visual Science, Volume 55 and Issue 13: http://iovs.arvojournals. org/article.aspx? articleid=2267338. The actual report, however, has never been published.

\section{Disclosure}

The authors report no conflicts of interest in this work.

\section{References}

1. Miyake K, Matsuda M, Inaba M. Corneal endothelial changes in pseudoexfoliation syndrome. Am J Ophthalmol. 1989;108(1):49-52.

2. Quiroga L, Lansingh VC, Samudio M, Peña FY, Carter MJ. Characteristics of the corneal endothelium and pseudoexfoliation syndrome in patients with senile cataract. Clin Experiment Ophthalmol. 2010;38(5): 449-455.

3. Skuta GL, Parrish RK 2nd, Hodapp E, Forster RK, Rockwood EJ. Zonular dialysis during extracapsular cataract extraction in pseudoexfoliation syndrome. Arch Ophthalmol. 1987;105(5):632-634.

4. Drolsum L, Haaskjold E, Davanger M. Pseudoexfoliation syndrome and extracapsular cataract extraction. Acta Ophthalmol (Copenh). 1993; 71(6):765-770

5. Drolsum L, Haaskjold E, Sandvig K. Phacoemulsification in eyes with pseudoexfoliation. J Cataract Refract Surg. 1998;24(6):787-792.

6. Shingleton BJ, Heltzer J, O’Donoghue MW. Outcomes of phacoemulsification in patients with and without pseudoexfoliation syndrome. J Cataract Refract Surg. 2003;29(6):1080-1086.

7. Hayashi K, Manabe S, Yoshimura K, Kondo H. Corneal endothelial damage after cataract surgery in eyes with pseudoexfoliation syndrome. $J$ Cataract Refract Surg. 2013;39(6):881-887.

8. Wirbelauer C, Anders N, Pham DT, Wollensak J. Corneal endothelial cell changes in pseudoexfoliation syndrome after cataract surgery. Arch Ophthalmol. 1998;116(2):145-149.

9. Kaljurand K, Teesalu P. Exfoliation syndrome as a risk factor for corneal endothelial cell loss in cataract surgery. Ann Ophthalmol (Skokie). 2007;39(4):327-333

10. O’Brien PD, Fitzpatrick P, Kilmartin DJ, Beatty S. Risk factors for endothelial cell loss after phacoemulsification surgery by a junior resident. J Cataract Refract Surg. 2004;30(4):839-843.

11. McCarey BE, Edelhauser HF, Lynn MJ. Review of corneal endothelial specular microscopy for FDA clinical trials of refractive procedures, surgical devices, and new intraocular drugs and solutions. Cornea. 2008;27(1):1-16.

12. Armitage WJ, Dick AD, Bourne WM. Predicting endothelial cell loss and long-term corneal graph survival. Invest Ophthalmol Vis Sci. 2003;44(8):3326-3331.

13. Lass JH, Gal RL, Ruedy KJ, et al. An evaluation of image quality and accuracy of eye bank measurement of donor cornea endothelial cell density in the specular microscopy ancillary study. Ophthalmology. 2005; 112(3):431-440.

14. Miyata K, Nagamoto T, Maruoka S, Tanabe T, Nakahara M, Amano S. Efficacy and safety of the soft-shell technique in cases with a hard lens nucleus. J Cataract Refract Surg. 2002;28(9):1546-1550.

15. Ursell PG, Spalton DJ, Tilling K. Relation between postoperative blood-aqueous barrier damage and LOCS III cataract gradings following routine phacoemulsification surgery. Br J Ophthalmol. 1997; 81(7):544-547. 
16. Davison JA, Chylack LT. Clinical application of the lens opacities classification system III in the performance of phacoemulsification. $J$ Cataract Refract Surg. 2003;29(1):138-145.

17. Dick HB, Kohnen T, Jacobi FK, Jacobi KW. Long-term endothelial cell loss following phacoemulsification through a temporal clear corneal incision. J Cataract Refract Surg. 1996;22(1):63-71.

18. Walkow T, Anders N, Klebe S. Endothelial cell loss after phacoemulsification: relation to preoperative and intraoperative parameters. $J$ Cataract Refract Surg. 2000;26(5):727-732.

19. Hayashidera T, Nejima R, Hasegawa Y, et al. The effect of pseudoexfoliation syndrome on corneal endothelial cell loss after cataract surgery. Jpn J Clin Ophthalmol. 2016. In press 2016.

20. Ogino K, Koda F, Miyata K. Damage to cultured corneal endothelium caused by ultrasound during phacoemulsification. Nippon Ganka Gakkai Zasshi. 2010;97(11):1286-1291.

21. Jonas JB, Nangia V, Gupta R, et al. Anterior chamber depth and its associations with ocular and general parameters in adults. Clin Experiment Ophthalmol. 2012;40(6):550-556.

22. Storr-Paulsen A, Norregaard JC, Ahmed S, Storr-Paulsen T, Pedersen TH. Endothelial cell damage after cataract surgery: divide-andconquer versus phaco-chop technique. J Cataract Refract Surg. 2008; 34(6):996-1000.
23. Arnarsson A, Damji KF, Sverrisson T, Sasaki H, Jonasson F. Pseudoexfoliation in the Reykjavik Eye Study: prevalence and related ophthalmological variables. Acta Ophthalmol Scand. 2007;85(8):822-827.

24. Zheng X, Sakai H, Goto T, et al. Anterior segment optical coherence tomography analysis of clinically unilateral pseudoexfoliation syndrome: evidence of bilateral involvement and morphologic factors related to asymmetry. Invest Ophthalmol Vis Sci. 2011;52(8):5679-5684.

25. Sufi AR, Singh T, Mufti AA, Rather MH. Outcome of phacoemulsification in patients with and without Pseudoexfoliation syndrome in Kashmir. BMC Ophthalmol. 2012;12:13.

26. Chen M, Lamattina KC, Patrianakos T, Dwarakanathan S. Complication rate of posterior capsule rupture with vitreous loss during phacoemulsification at a Hawaiian cataract surgical center: a clinical audit. Clin Ophthalmol. 2014;8:375-378.

27. Zimmermann N, Wünscher M, Schlötzer-Schrehardt U, Erb C. Corneal endothelial cell density and its correlation with the severity of pseudoexfoliation. Klin Monbl Augenheilkd. 2014;231(2):158-163.
Clinical Ophthalmology

\section{Publish your work in this journal}

Clinical Ophthalmology is an international, peer-reviewed journal covering all subspecialties within ophthalmology. Key topics include: Optometry; Visual science; Pharmacology and drug therapy in eye diseases; Basic Sciences; Primary and Secondary eye care; Patien Safety and Quality of Care Improvements. This journal is indexed on

Submit your manuscript here: http://www.dovepress.com/clinical-ophthalmology-journal

\section{Dovepress}

PubMed Central and CAS, and is the official journal of The Society of Clinical Ophthalmology (SCO). The manuscript management system is completely online and includes a very quick and fair peer-review system, which is all easy to use. Visit http://www.dovepress.com/ testimonials.php to read real quotes from published authors. 